\title{
With or Without You: \\ Market Quality of Floor Trading when Screen Trading closes \\ early $^{*}$
}

\author{
Dirk Schiereck ${ }^{\dagger}$, Christian Voigt ${ }^{\ddagger}$
}

\begin{abstract}
We examine the effects of the reduction of the daily business hours of a screen based main trading system while a parallel floor based trading system keeps on operating. We provide evidence that liquidity improves while informed trading and informational efficiency of prices decrease at the floor based trading system as a result of the no longer operating main market. While prior research on parallel trading focuses on changes due to a growing number of trading venues, we present first evidence on market effects when the main trading platform reduces trading hours.
\end{abstract}

Jel Classification: G14

Keywords: parallel trading, liquidity, information based trading, market efficiency

\footnotetext{
* We thank the Deutsche Börse AG for providing the data.

$\dagger$ Endowed Chair for Banking and Finance, European Business School (ebs), International University; Schloß Reichartshausen; 65375 Oestrich-Winkel / Germany; Tel.: +49 (6723) 69991 213; Fax: +49 (6723) 69991 216; Email: dirk.schiereck@ebs.de

* Endowed Chair for Banking and Finance, European Business School (ebs), International University; Schloß Reichartshausen; 65375 Oestrich-Winkel / Germany; Tel.: +49 (6723) 69991 215; Fax: +49 (6723) 69991 216; Email: christian.voigt@ebs.de
} 


\section{Introduction}

Most highly developed stock markets are characterized by a number of parallel operating trading systems or stock exchanges. Despite strong arguments for consolidation markets are fragmented and remain so for long periods of time. Madhavan (2000) describes this phenomenon as "network externalities puzzle". On the one hand, advocates of parallel trading markets name positive effects such as decrease monopolistic rents due to increased competition. ${ }^{1}$ On the other hand, opponents point out that for example consolidation leads to higher liquidity externalities. ${ }^{2}$

Another string of literature concentrates on the changes in market quality by the closing of the main trading system and the beginning of after market trading or the ongoing trading on ECNs or regional stock exchanges and find that trading during after hours is mostly illiquid. The price discovery is lower than during the day and consequently price efficiency is poor. ${ }^{3}$ The results are driven by two factors. Firstly, the main stock exchange does not operate during after hours. Secondly, results are influenced by the intraday pattern of trading. ${ }^{4}$

All these studies either analyze event oriented the entrance of a new trading platform or over a long time period the co-existence of established markets. In both cases, the number of trading alternatives is stable or even growing. Market participants here decide whether to stay or go. But we hardly had ever the opportunity to analyze an event where market participants suddenly had to switch because the main market reduced its trading hours. This happened in Germany in $2003^{5}$ and offers the opportunity to study how traders changed their behavior in respond to this reduction. They have three alternatives: (a) to finish their activities earlier, (b) to wait until next trading day or (c) to switch to another trading platform. Given that the screen based trading platform is the main trading system in Germany, combining most of the

1 See Boehmer and Boehmer (2003), Battalio (1997), Wahal (1997), Mayhew (2002), Fong, Madhavan and Swan (2001), DeFontnouvelle, Fishe and Harris (2000), Conrad, Johnson and Wahal (2003), Biais (1993) or Chowdhry and Nanda (1991).

2 See Bernhardt and Hughson (1997), Amihud, Lauterbach and Mendelson (2003), Arnold, Hersch, Mulherin and Netter (1999), Madhavan (1995), Jain (2002), Pagano (1989a), Pagano (1989b).

3 See Barclay and Hendershott (2003), Barclay and Hendershott (2004) and McInish, van Ness and van Ness (2002).

4 Numerous studies provide evidence that trading activities display intraday pattern, such as: Wood, McInish and Ord (1985), Jain and Joh (1988), McInish and Wood (1992), Abhyankar, Ghosh, Levin and Limmack (1997) and Chan, Chung and Johnson (1995).

5 The trading system Xetra of Deutsche Börse AG opened every business day from 9:00 a.m. to 8:00 p.m. in the past. Since Nov. 3rd, 2003 Xetra operates every business day only until 5:30 p.m. For further details see Section 2 and 3. 
trading volume, it is obviously that this event must have some impact on traders of the other markets.

The understanding of the event is important, because it shed light on the relationship of parallel markets. Given the ongoing talks about the consolidation of trading venues across Europe, it is important to examine the behavior of investors when an existing main trading system stops to operate and investors have to adapt. The effects of reducing the operating hours of a main trading system are expected to be much stronger then of a small trading platform. We do not believe that this event is simply a reversal of an introduction of a new large-scale trading platform. The major difference is liquidity externalities, which could be destroyed by this event. So far we are not certain how much of the pre-event conditions have to be contributed to positive liquidity externalities. If liquidity externalities are a major contributor to trading, it is possible that the floor based trading platform is significantly negatively affected. This again could start up a viscous circle, which might force the floor based trading venue to stop operating during the evening as well.

To our knowledge, this situation has hardly ever been subject of any research. One exception is a recent study by Hendershott and Jones (2005). They analyze the market of three exchange-traded-funds when the Island electronic communication network stopped displaying its limit order book, while it was the dominant venue. Their results show, that trading activity and price discovery decreases, leading to in overall worsening of market quality. After one year of non-display, Island redisplays quotes again. Hendershott and Jones (2005) show that the second event is much more modest and does not simply reverse the effects. In contrast to our study does Island not stop to operate but stops displaying quotes to "any" market participant. But in our case the screen based trading venue stops completely during the evening. Both events have in common that they present a major limitation of trading. Hendershott and Jones (2005) analyze the impact on three different exchange traded funds. We are able to support their results for at least the first event with a much broader sample.

Aim of this paper is to analyze the impact of this event on one of the floor based exchanges in Germany, when the main screen trading platform reduced its operating hours. In the study we illustrate the changes of liquidity, informed trading and market efficiency as a direct result of the event. This study documents the dynamic behavior of investors on changes in market structure. 
We believe that the documented changes are associated with the change in operating hours at the screen based trading system. But we point out that this investigation analyzes a single event and that therefore the statistical ability to attribute changes to the event is limited. Boehmer, Saar and Yu (2005) face a similar problem in their study. They provide additional robustness tests to show that the reported results are not due to secular trend. The similar approach is applied in this study. We control for secular trends not caused by the event by computing all measures for regular operating hours, too.

With these caveat in mind, our analysis suggests that the earlier closing of the screen based trading system is mostly beneficial for the floor based stock exchanges. This finding is important for several reasons. Firstly, it provides evidence that those floor based stock exchanges are able to profit from this event by gaining additional liquidity. Secondly, it shows that market structure has an impact on the behavior of investors, by documenting that especially uninformed traders willing to trade in highly liquid stocks make the transfer. Thirdly, despite a decrease of market efficiency an increased number of traders are still willing to trade during evening hours. This implies that obviously waiting cost until next day are much higher for them. Thus, evening hour trading yields added value, despite less favorable market conditions.

The rest of the paper is structured as follows: Section 2 provides an overview of the institutional setting of the examined stock exchange and the German equity market. In Section 3 we review the related literature and derive our testable hypotheses. Section 4 presents a descriptive statistic of the employed data sample. Section 5 analyzes the change in level of liquidity at the FSE. Than, Section 6 examines the level of informed trading and the corresponding changes subsequent the event. In Section 7 we determine the informational efficiency of prices. Finally, in Section 8 we conclude.

\section{The Structure of the German Equity Markets}

Theissen (2003a) describes the German equity ${ }^{6}$ market as horizontally and vertically fragmented. In the vertical dimension the market is divided into three segments, namely

\footnotetext{
${ }^{6}$ For further readings on the German equity markets see Demarchi and Foucault (2000) and Commerton-Forde and Rydge (2004).
} 
"Freiverkehr", "General Standard" and "Prime Standard". The unregulated "Freiverkehr" is the least regulated segment, followed by the "General Standard". It is designed for smaller companies with a domestic focus. The "Prime Standard" is the highest regulated segment, aiming at internationally visible companies. Among many other requirements, those companies have to be included in one of the indices calculated and published by the Deutsche Börse AG. ${ }^{7}$ The structure of the most important German indices is shown in Figure I. The DAX is the blue chip index, including the 30 most liquid stocks. Than, 50 MDAX securities and 50 SDAX securities are following each representing the "old economy". The TecDAX comprises the 30 most liquid high tech firms, thus representing the "new economy". Table I shows the market capitalization of the indices and all domestic securities. We see that the DAX index is dominating all other indices and represents nearly half of the total market capitalization. Even though the MDAX is significantly smaller than the DAX, it is still approximately eight times bigger than the SDAX. Furthermore, we observe that all indices develop parallel across time.

In the horizontal dimension, the German equity market is fragmented between seven stock exchanges and one electronic trading system. The Deutsche Börse AG is hugely dominating the equity market by operating electronic trading system Xetra and the floor based trading platform Frankfurt Stock Exchange. Additionally, there are six other stock exchanges located in Berlin-Bremen, Düsseldorf, Hamburg, Hannover, Munich, and Stuttgart. There are not considered in this study, given their extremely small market share ranging between 0.87 percent and 5.75 percent depending on the index. (See Table II)

Reck (2001) and Theissen (2003a) provides a description of the trading system of Xetra. Xetra was introduced in 1997 and is the successor of IBIS. Xetra is fully automated trading system based on open limit order book providing continuous trading. (also referred to as continuous double auction). The computerized order book manages all incoming market and limit orders. Orders are automatically matched by the system based on price and time priority. The operating hours before Nov. $3^{\text {rd }}, 2003$ were 9:00 a.m. to 8:00 p.m. and after Oct. $31^{\text {st }}$, 2003 are 9:00 a.m. to 5:30 p.m. ${ }^{8}$ Every trading session starts, ends and is twice interrupted by call auctions. All securities traded at the market are ranked according to their liquidity.

\footnotetext{
${ }^{7}$ The membership of the security in the CDAX does not qualify for "Prime Standard", given that this index includes all listed companies.

${ }^{8}$ The first day with the new Xetra operating hours was Monday Nov. $3^{\text {rd }}, 2003$. The last day of trading with the old operating hours was Friday Oct. 31 $1^{\text {st }}, 2003$.
} 
Securities belonging to the low-liquidity category are only traded when they have at least one "Designated Sponsor". Those "Designated Sponsor" are required to quote bid and ask prices and participate in call auctions. They are responsible for providing the minimum requirements of liquidity. For quality assurance all "Designated Sponsor" are regularly rated by the exchange and the results are made public.

Theissen (2003a) and Theissen (2003b) provides an overview on the trading system of the floor of the FSE. Trading at FSE is organized similar to the NYSE. A "Kursmarkler" (similar to the specialist) conducts trading, and has exclusive access to the information in the limit order book. One difference between FSE and NYSE is noteworthy. The market maker at the NYSE is required to trade with anybody, based on his quotes. The "Kursmarkler" may trade on his own account in addition, but is not obliged to do so. He quotes continuously bid and ask prices (called "Taxen"), which represent either limit orders in his order book or his own willingness to trade. The operating hours are between 9:00 a.m. and 8:00 p.m. The "Kursmarkler" conducts at 9:00 a.m. an opening call auction goes on to a continues trading session. ${ }^{9}$ Finally, he ends the trading day with a closing call auction.

\section{Related Literature and Testable Hypotheses}

The trading system Xetra of Deutsche Börse AG opened every business day from 9:00 a.m. to 8:00 p.m. in the past. Since Nov. $3^{\text {rd }}, 2003$ Xetra operates every business day only until 5:30 p.m. This change in operating hours influences all market participants willing to trade after 5:30 p.m. During regular business hours (9:00 a.m. - 5:30 p.m.) an investor has a wide choice of stock exchanges available in Germany (namely, Berlin-Bremen, Düsseldorf, HamburgHannover, München, Frankfurt, Stuttgart and Xetra), where he can trade identical equity securities. But trading during evening hours (between 5:30 p.m. and 8:00 p.m.) is limited to all but Xetra. This is a significant limitation for investors, because Xetra combines the largest market share of trading volume in Germany as shown in Table II.

Investors which used to trade on Xetra now have three options for trading during evening hours. Either they choose to trade earlier, they choose to wait until the next trading day or they switch to one of the other stock exchanges. As those particular investors choose to trade

\footnotetext{
9 A large number of securities (but none included in the sample) is not too illiquid for continues trading. Thus, only daily call auctions are conducted. The same applies for Xetra.
} 
on Xetra beforehand, it can be assumed that they view all the other stock exchanges as inferior compared to Xetra. Therefore, investors wanting to trade on Xetra during evening hours face a trade-off between trading at a sub-optimal point in time (before or next day) and an inferior transaction process at a different market. Every investor solves this trade-off independently from each other, depending on his preferences and own cost structure. Analyzing the trade-off of investors in detail is not focus of this paper. We rather focus at the final results by analyzing the level of liquidity at FSE. This analysis provides evidence, whether FSE could profit from this change by gaining additional order flow or investors decide to wait until the next trading day. We expect to observe an improvement of liquidity at least to some extent. We do not expect that all investors transfer to the FSE, because some investors are more affected by the changes than other and consequently are less prone to switch. We test these predictions in the following hypothesis:

H1: The liquidity at the FSE increased significantly after the change in opening times at Xetra.

Jain, Siang, McInish and Taechapiroontong (2003) analyze informed trading at the anonymous SETS and a non-anonymous voluntary dealer market. They show that informed traders prefer SETS, while the dealer market is able to compete effectively for uninformed order flow. Barclay, Hendershott and McCormick (2003) show that informed traders are more willing to trade at ECNs, due to a greater degree of anonymity. The study by Grammig, Schiereck and Theissen (2001) are able to provide evidence that the probability of informed trading is higher at IBIS compared to the floor of FSE. They point out that at the FSE the "Kursmarkler" knows the identity of his counterparty, while at IBIS this is not the case. Therefore, informed traders prefer an anonymous electronic trading system, because they can trade longer on their information. Thus, informed traders are less likely to transfer to one of the other stock markets and more likely to wait or trade earlier until the next trading day, as they are preferring anonymity stronger. Hence, we estimate the probability of informed trading. We employ the methodology proposed by Easley, Kiefer, O'Hara and Paperman (1996) at the FSE. We expect to observe that informed and uninformed trading will increase, because some investors are expected to switch trading systems. But we anticipate that the arrival rate of uninformed traders increases stronger compared to the arrival rate of informed traders, resulting in a decrease in the probability of informed trading. We test whether the following hypothesis holds. 
H2: The arrival rate of uninformed traders increased stronger than the arrival rate of informed traders after the change in opening times at Xetra.

The abolishment of trading during evening hours does not only yield potentially positive effects for the regional stock exchanges. In the following text we argue that a decreased liquidity, informed trading and pre-trade transparency leads to a decline in market efficiency. Hasbrouck (1995) analyzes the proportional contribution to the innovation in the common efficient price for homogeneous or closely-linked securities of multiple markets. He provides evidence that the price discovery takes mainly place (a median 92.7 percent information share) at the New York Stock Exchange (NYSE) and not at the US regional stock exchanges. Theissen (2001) analyzes price discovery in Xetra and FSE. They find that both markets contribute to price discovery. The contributions of the two trading systems to the process of price discovery are almost equal, with some evidence that contribution is larger. Thus, the FSE profited from the price discovery provided by Xetra during evening hours before the event. Now Xetra closes early and price discovery has to be produced solely by the FSE. If it is not able to provide additional price discovery stock prices become less efficient and overall market quality decreases.

A decrease of the informational efficiency of prices during evening hours is expected for the following reasons: We showed earlier that some investors are less likely to transfer than others. All those who decide to trade at a different point of time are lost to the evening hour trading across all stock exchanges in Germany. Chordia, Roll and Subrahmanyam (2005) show that liquidity is positively related to market efficiency. They argue that market efficiency is not immune to frictions such as illiquidity and higher liquidity is associated with more trading on private information, which increases price efficiency. Thus informational efficiency is expected to decrease.

Boehmer, Kelley and Pirinsky (2005) prove that there is a positive relationship between fraction of informed trading and efficient prices, arguing that institutional investors are better informed and thus increase informational efficiency. We argued earlier, that we expect a stronger increase of the arrival rate of uninformed traders than informed traders. Therefore, we anticipate that a decrease of the observed price efficiency. 
Additionally, Xetra functions as an open limit order book, providing detailed information on depth and liquidity of the market to potential investors, while other German stock exchanges are not. Thus, pre-trade transparency of German stock markets hugely decreases in German stock markets after 5:30 p.m. every trading day. Glosten (1999) and Baruch (2005) predict that an improvement of transparency leads to an increase of informational efficiency of prices. Boehmer, Saar and Yu (2005) analyze the introduction of NYSE's Open book service that provides limit order book information to traders off the exchange floor. Their results suggest that an increase in pre-trade transparency improves informational efficiency of prices. ${ }^{10}$ The early closing of Xetra represents a decrease of pre-trade transparency. Thus a decline of market quality could be expected at the FSE. Summarizing, we anticipate that decreased liquidity, informed trading and pre-trade transparency cause a reduction informational efficiency. We test our expectations in the following hypothesis:

H3: The informational efficiency of prices decreased after the change in opening times at Xetra.

The study by Theissen (2002) compares trading at IBIS and FSE. He shows that both trading systems have their advantages. While the electronic trading system displays lower bid-ask spreads for more liquid stocks, transaction costs appear lower for less liquid stocks at the floor trading. He explains those differences with a trade-off between operational cost (electronic stock exchanges are more efficient) and adverse selection cost (market structure of floor trading reduces adverse selection component of bid-ask spread). Thus, investors willing to trade more in liquid stocks are less likely to transfer to one of the other stock markets and more likely to wait until the next trading day, as they are stronger preferring a electronic trading system. Therefore, we will differentiate our reported results according to low and high trading volume. The testable implications that arise as discussed above, are stated in the following related hypotheses:

H4a: Liquid and illiquid stocks respond differently at the change of opening times at Xetra in regard to liquidity.

\footnotetext{
${ }^{10}$ In contrast, the model of Madhavan, Porter and Weaver (2005) show that grater transparency leads to wider spreads, lower depth and higher volatility. But they do not base their empirical analysis on detailed order level data, as Boehmer, Saar and Yu (2005) do. Hence, we follower their line of argument and assume that increased transparency leads to increase of market quality.
} 
H4b: Liquid and illiquid stocks respond differently at the change of opening times at Xetra in regard to arrival rates of (un)informed traders.

H4c: Liquid and illiquid stocks respond differently at the change of opening times at Xetra in regard to market efficiency.

\section{Data}

The sample for the FSE covers 63 days from $01 / 10 / 2003$ to $027 / 02 / 2004$. The following time periods are included in the sample: 10/01-10/31/2003 (23 trading days); 11/01-11/21/2003 (15 trading days); 01/05-01/23/2004 (15 trading days) and 02/16-02/27/2004 (10 trading days). Thus, our sample includes 23 trading days prior and 40 trading days after the event. Table II shows that securities included in DAX and MDAX are traded more actively on Xetra, as securities included in SDAX. The more a security is traded on Xetra, the more it will be affected by the change in operating hours. Thus, the sample includes all 30 securities of DAX and another 49 securities selected from MDAX and TecDAX.

Transaction data comprises time-stamped transaction prices, volume data, unique transaction identifier and trade-direction identifier. The original data sample included 828.310 transactions. We excluded 4.948 transaction recorded twice, based on the unique transaction identifier. No further adjustments are necessary. ${ }^{11}$ Our final data sample includes 823.362 transactions.

Descriptive statistics are given in Table III. We argued before that we expect different results for highly liquid and less liquid stocks. Therefore, stocks have been sorted into two groups according their trading volume. Apparently, the sample covers a wide range of market capitalizations and number of transactions. The less liquid stocks have a median market capitalization of 1.1 billion Euro and a median of 2,500 transactions, while highly liquid stocks have a median market capitalization of 12.1 billion Euro and a median of 12,089 transaction are included in the sample. A Pair-wise Mann-Whitney $U$ test shows that the differences are statistical significant. The average free float for stocks with low trading volume is about 55.00 percent while stocks with high trading volume have a mean of 75.00

\footnotetext{
${ }^{11}$ Additionally, we controlled for (a) transactions outside the daily operating hours, and (b) transactions on days not included in the sample.
} 
percent. A Pair-wise Mann-Whitney $U$ test confirms that this difference is not statistical significant. Thus, we are confident that even the sample with less liquid stocks is suitable for our analysis.

\section{Liquidity and Trading Activity}

We pointed out earlier that investors at Xetra which are willing to trade after 5:30 p.m. face a trade-off. On the one hand they incur the cost of sub-optimal point of transaction time. On the other hand they incur the cost of using an inferior trading system. If a significant number of potential investors decide to trade on different stock exchange, FSE might be able to profit from the event, as their liquidity increases. Therefore, we analyze the trading activities at the FSE.

We employ the following transaction data based measures as proxy for liquidity. The measures are trade size in Euro $(T S)$, trade duration $(T D)$ and turnover duration $(T O D)$. We follow the definition of trade duration by Hautsch (2004). He defines trade duration as the time between two consecutive trades. Trade duration accounts for the frequency of trading, but does not measure differences in turnover. Thus, we calculate turnover duration, which describes the time that a stock needs to absorb a certain amount of money. This measure is based on volume duration suggested by Gouriéoux, Jasiak and Le Fog (1999). Volume duration describes the time that a stock needs to absorb a certain number of stocks. Unfortunately, this measurement does not allow a comparison across different stocks. Thus, we extend this measurement by accounting for differences in price levels. Alternatively, turnover duration can be viewed as the reciprocal measure of the turnover measure (total turnover over a certain period) suggested by Chan, Chung and Fong (2002). The threshold for turnover duration is defined as 10,000 Euros. All trade information observed during a trading session and across all securities is aggregated to one trade information, using the equal weighted mean of this trading session.

Table IV presents an analysis of the liquidity at the FSE around the change in operating hours at Xetra. The sample is divided into "Before Nov. 3rd, 2003" / "After Oct. 31st, 2003", trading between during regular hours (9:00 a.m. - 5:30 p.m.) / during evening hours (5:30 p.m. - 8:00 p.m.) and high / low trading volume. We report medians of trade size, trade duration and turnover duration. Pair-wise Mann-Whitney U tests are used to test the null-hypothesis that two samples are drawn from identical populations. 
Our results show that highly liquid and less liquid stocks differ significantly. Trade duration for highly liquid securities ranges between $1-8$ minutes, while trade duration for less liquid stocks ranges between $11-41$ minutes. A similar picture evolves considering turnover duration. Stocks with high trading volume range between $1-3$ minutes and stocks with low trading volume range between $7-17$ minutes.

We see that trade duration and turnover duration improved in all samples across time. We observe that trade duration and turnover duration increases during regular hours and during evening hours. We attribute the improvement during regular operating hours to a secular trend, which is not driven by the examined event. But we see a stronger growth during the evening hours. We attribute this additional increase - beyond the growth rates observed during regular operating hours - to the change of opening hours of Xetra. Additionally, we note that these effects are stronger for highly liquid stocks compared to less liquid stocks.

Comparing turnover duration with trade duration reveals that turnover duration reacts relatively stronger in the evening for stocks with high trading volume. This indicates that not only trading frequency but also trading volume increased during evening hours. Thus, trade size is examined. We see that at the trade size across all samples stagnates or even slightly decreases over time, except for highly liquid stocks during evening hours. We observe a sharp increase from $6.965 €$ up to $12.261 €$ for liquid stocks during the evening. Before the event, Trade size is similar (or slightly lower) compared to trading during regular hours. After the event trade size increases strongly and is even larger than in any other sub-sample of this time period. This implies that trading during evening hours is strongly affected by the event. Two explanations are possible for this effect. Firstly, the already active investors at FSE changed their preferred trade size. Secondly, FSE attracted new investors, which prefer a larger trade size, than the already active investors at those stock exchanges. We believe that the second possibility is true, because of a higher trading frequency after the event, as discussed above.

Summarizing, the frequency of trading at the FSE increased after the change of operating hours at Xetra. The increase appears to be stronger during evening hours. This holds especially true for securities with high trading volume. The extremely strong increase in trade size provides further indication for additional investors. Thus, we conclude that some of the 
investors decided to transfer their trading activities to FSE. These observations are consistens with Hypothesis 1 and $4 a$.

\section{Probability of Informed Trading}

In this section we analyze the change in probability of informed trading at the FSE. We showed in Section 5 that the trading activity increased in FSE after the change in operating hours at Xetra. Now, we will examine, whether more informed or uninformed traders transferred to the regional stock exchanges. Grammig, Schiereck and Theissen (2001) show that the probability of informed trading is significantly lower in the FSE compared to IBIS. They argue that a high degree of anonymity is associated with a higher probability of informed trading. Hence, we anticipate that the arrival rate of uninformed traders increases stronger compared to informed traders, leading to an overall decrease of the probability of informed trading. Following now, we briefly introduce the model for estimating the probability and then we present our results.

\subsection{Methodology}

Information-based trades are not directly observable. Therefore, a structural microstructure model is applied to make inferences about it. According to Easley, Hvidkjaer and O'Hara (2002): "microstructure models can be viewed as learning models in which market makers watch market data and draw inferences about the underlying true value of an asset". Following Easley, Kiefer, O'Hara and Paperman (1996), the trading process and the market maker's learning process can be modeled and used to make an inference about the probability of information based trading.

For estimating the probability of informed trading the model suggested in Easley, Hvidkjaer and O'Hara (2002) will be applied. Trading can be depicted as a game that repeats over $t=$ $1 \ldots T$ days. Trades occur over the days in discrete time, within each trading day trades take place in continuous time. Between each day nature determines whether a relevant information event occurs or not. Information events are independently distributed and take place with probability $\alpha$. The events are bad news with probability $\delta$ and are good news with probability $(1-\delta)$. Good news imply that the value of the asset increases from $V_{t}^{*}$ to $V_{t}^{h}$ and bad news imply a decrease in value from $V_{t}^{*}$ to $V_{t}^{l}$, respectively. Thus, it is assumed, that $V_{t}^{l}<V_{t}^{*}<V_{t}^{h}$ . The trade orders arrive every day following a Poisson processes. The market maker executes 
orders as they arrive based on the previously quoted bid and ask prices. Uninformed traders trade for liquidity reason. It is assumed that orders of uninformed traders arrive at rate $\varepsilon$. Informed traders buy if they observe good news and sell if they observe bad news. The arrival rate of orders of informed trades is $\mu$. Every time an order arrives, the market maker observes the price and updates his expectations. This process is described in Figure II.

A number of papers ${ }^{12}$ show how to use this structural model to work backwards and provide specific estimates for the risk of information based trading. They describe that this structural microstructure model can be estimated using a maximum likelihood function. The function is

$$
\begin{aligned}
L\left(\Theta_{t} \mid B_{t}, S_{t}\right)= & (1-\alpha) e^{-\varepsilon} \frac{\varepsilon^{B}}{B !} e^{-\varepsilon} \frac{\varepsilon^{S}}{S !} \\
& +\alpha \delta e^{-\varepsilon} \frac{\varepsilon^{B}}{B !} e^{-(\mu+\varepsilon)} \frac{(\mu+\varepsilon)^{S}}{S !} \\
& +\alpha(1-\delta) e^{-(\mu+\varepsilon)} \frac{(\mu+\varepsilon)^{B}}{B !} e^{-\varepsilon} \frac{{ }_{\varepsilon} S}{S !},
\end{aligned}
$$

where $B_{t}$ and $S_{t}$ are the total number of buy and sell trades per day and $\Theta_{t}(\alpha, \delta, \varepsilon, \mu)$ is the parameter vector per day. This likelihood function represents a mixture of distributions weighted with the probabilities of a "good news day" $\alpha(1-\delta)$, a "bad news day" $\alpha \delta$ and a "no event day" $(1-\alpha)$. As days are independent from each other, the likelihood of observing data $M=\left(B_{t}, S_{t}\right)_{t=1}^{T}$ over T days is the product of the daily likelihoods.

$$
L=(M \mid \Theta)=\prod_{t=1}^{T} L\left(\Theta \mid B_{t}, S_{t}\right)
$$

Following Easley, Engle, O'Hara and Wu (2000) the likelihood function can be rearranged for computational efficiency in the following way:

\footnotetext{
${ }^{12}$ See Easley, Kiefer and O'Hara (1997a), Easley, Kiefer and O'Hara (1997b), Easley, Kiefer, O'Hara and Paperman (1996) and Easley, Hvidkjaer and O'Hara (2002).
} 


$$
\begin{aligned}
L(M \mid \Theta)=\sum_{t=1}^{T}[ & -2 \varepsilon+M \ln x+(B+S) \ln (\mu+\varepsilon)] \\
& \quad+\sum_{t=1}^{T} \ln \left[\alpha(1-\delta) e^{-\mu} x^{S-M}+\alpha \delta e^{-\mu} x^{B-M}+(1-\alpha) x^{S+B-M}\right],
\end{aligned}
$$

where $M=\min (B, S)+\max (B, S) / 2$ and $x=\varepsilon /(\mu+\varepsilon)$. The variable $x$ can be interpreted as the ratio of the arrival rates of "wrong trades" to that of "right trades". A "wrong trade" is defined as a buy (sell) in presence of a bad (good) signal and a right trade is vice versa.

The summary proxy for asymmetric information is the probability of informed trading $(P I N)$. This is the unconditional probability that a randomly selected trade originates from an informed trader and is calculated as follows:

$$
P I N=\frac{\alpha \mu}{\alpha \mu+2 \varepsilon}
$$

The original model suggest by Easley, Kiefer, O'Hara and Paperman (1996) assumes a market with a market maker. As discussed earlier, FSE does not posses a market maker. Thus, we should conclude that this model cannot be applied for this data. But Grammig, Schiereck and Theissen (2000) show that applying Easley, Kiefer, O'Hara and Paperman (1996) to an open limit order book does not necessarily violate any assumption. They argue that one market maker behaves similar to several market makers, as shown in Kyle (1985). Grammig, Schiereck and Theissen (2000) stipulate, that all liquidity providing investors can be regarded as market makers and all liquidity demanding investors can be regarded as either informed or uninformed traders. This bases on the assumption that informed trader do not provide and only demand liquidity, as suggested by Glosten (1994). Even though Bloomfield, O'Hara and Saar (2005) and Anand and Martell (2001) argue that this assumption does not necessarily hold true. Theissen (2002) provides empirical evidence that the adverse-selection component of the bid-ask spread of DAX-companies yields approximately 95.9 percent of the effective spread. This implies that, liquidity providers are hardly able to make a profit on the spread, because they lose most of the spread to informed traders. Thus, the assumption that liquidity providing investors can be regarded as market markers appears to be reasonable and Easley, Kiefer, O'Hara and Paperman (1996) can be applied to an open limit order book. 
As pointed out before, Xetra is an open limit order book but FSE is not. FSE exhibits also an order driven market but the order book is only visible to the "Kursmarkler". We believe that the arguments stated by Grammig, Schiereck and Theissen (2000) can be applied for FSE as well, because it is a order driven markets, too. Investors at the FSE are able to provide liquidity via limit orders or demand liquidity via market orders, similar to an open limit order book. In contrast to an open limit order book, investors only observe bid and ask quotes. Those quotes represent either limit orders in the order book of the "Kursmarkler" or his own willingness to trade. This difference in market structure implies a difference in the level of transparency for the Xetra open limit order book and FSE. But given the fact that liquidity demanding and liquidity providing investors are able to trade at FSE leads to the conclusion that the arguments by Grammig, Schiereck and Theissen (2000) can be applied for the FSE, too.

The original model by Easley, Kiefer, O'Hara and Paperman (1996) is applied to daily data. We change this model by dividing the day into two periods, namely trading during regular hours (9:00 a.m. - 5:30 p.m.) and trading during evening hours (5:30 p.m. - 8:00 p.m.). We do not believe that this change violates any assumptions. In Easley, Kiefer, O'Hara and Paperman (1996) it is assumed that prior to a trading session nature determines whether an information relevant to the value of the asset will occur. Whether a trading session equals a trading day or only a sub-period is not necessarily defined. Additionally, a similar approach is applied by Barclay and Hendershott (2003) and Goldstein, van Ness and van Ness (2002).

Computing the parameters of the vector $\Theta$ depends hugely on the starting values for the optimization procedure. Thus, we use for every estimation several different starting values, resulting in $n$ different possible results. We choose the vector $\Theta_{n}$, which fulfills the following restrictions. Firstly, every parameter of the vector $\Theta_{n}$ has to be greater zero. Secondly, $\alpha_{n}$ and $\delta_{n}$ of $\Theta_{n}$ have to be less than one, as they are interpreted as probabilities. Finally, the maximum likelihood function (3) has to maximum across all $n$ vectors $\left(\max \left[L\left(M \mid \Theta_{i}\right)\right]\right.$ with $i=1,2 \ldots n)$. If no suitable vector $\Theta_{n}$ has been found, we exclude this estimation from our further analysis. 


\subsection{Results}

Table $\mathrm{V}$ shows an analysis of the probability of informed trading at the FSE around the change in operating hours at Xetra. The sample is divided into "Before Nov. 3rd, 2003" / “After Oct. 31st, 2003", trading between during regular hours (9:00 a.m. - 5:30 p.m.) / during evening hours (5:30 p.m. - 8:00 p.m.) and high / low trading volume. The parameter $\mu(\varepsilon)$ is the arrival rate of (un)informed traders, $\alpha$ is the probability of an information event and $\delta$ is the probability that the information event is negative. The parameter PIN measures the probability of information based trading. We report medians across all securities. Pair-wise Mann-Whitney $U$ tests are used to test the null-hypothesis that two samples are drawn from identical populations.

Estimated parameters for stocks with low trading volume during evening hours are stable across time. This is quite surprising, considering a strong and statistically significant increase of (un)informed trading during regular hours. Thus, we have to conclude that despite an ongoing unobserved trend during regular business hours, trading during evening hours does not change significantly for stocks with low trading volume.

Stocks with high trading volume behave differently. The arrival rates of informed and uninformed traders show significant growth over time. The probability of informed trading is the highest for trading during evening hours before Nov. $3^{\text {rd }}, 2003$ compared to all other subsamples. We measure all samples a probability of approximately 0.21 but during evening hours it is up to 0.27 . The probability of informed trading during evening hours approached to the overall average, since Xetra is closing earlier. This observation is mainly driven by a relatively small arrival rate of uninformed traders at the beginning and a corresponding strong increase afterwards.

The probability that an information event takes place decreased in all sub-samples from before Nov. $3^{\text {rd }}, 2003$ to after Oct. $31^{\text {st }}, 2003$. This decrease is quite large, thus drives the probability of informed trading significantly. We believe that this change is due to an underlying, unobserved trend. So far we do not know any rational explanation why this change should be related to the early closing of Xetra. Therefore, a ratio $(\varepsilon / \mu)$ is reported in Table $\mathrm{V}$, presenting the fraction of arrival rate of uninformed traders over arrival rate of informed traders. We see that $\varepsilon / \mu$ behaves differently for highly and less liquid stocks. On the one hand, stocks with low trading volume only change statistically significant during 
regular operating hours. The ratio $\varepsilon / \mu$ decreases, meaning that the arrival rate of informed traders increases stronger than the arrival rate of uninformed traders. On the other hand, stocks with high trading volume change statistically significant during evening hours and the measure $\varepsilon / \mu$ increases, meaning that the arrival rate of uninformed traders increases stronger than the arrival rate of informed traders.

Thus, we conclude that our results are in line with our previously obtained results in Section 5 and that our observations support Hypothesis 2 and $4 \mathrm{~b}$. We show that the results differ hugely between highly liquid and less liquid stocks. Securities with low trading volume during evening hours appear to be stable across time, despite an unobserved trend during operating hours. And securities with high trading volume receive more uninformed traders compared to informed traders. We are certain that results are robust, because we control for the changes during regular operating hours.

\section{Informational Efficiency of Prices}

We argued in the introduction that information efficiency of prices might decrease for the following reasons: a decrease of liquidity, informed trading and pre-trade transparency during evening hours. Therefore, we estimate standard deviation of the pricing error as suggest by Hasbrouck (1993) as a measurement of price efficiency. For robustness check we compute the first-order autocorrelation of returns of prices. We examine whether the informational efficiency of prices decreased, after the earlier closing of Xetra. At first we introduce the methodology suggest by Hasbrouck (1993) and discuss first-order autocorrelation as proxy for informational efficiency. Secondly, we will report our results.

\subsection{Methodology}

There are several approaches measuring the informational efficiency of prices. Boehmer, Kelley and Pirinsky (2005) differentiate between three different methods. First approach is the analysis of long-term and short-term return variances, as done by Barnea (1974) or Hasbrouck and Schwartz (1988). The unit of time and the random walk suggests that the ratio of those variances should be one. Even though this test is simply to compute, it is sensitive to the horizons chosen for comparison. Second approach estimates prices changes associated with new information using liquidity ratios that relate volume to returns. (see Schreiber and Schwartz (1986)) But this approach does not differentiate between permanent and temporary 
price changes. Permanent price changes are caused by new information and therefore they are considered to be efficient. Temporary price changes are caused by noise representing illiquidity, which is not a useful measure for price efficiency. The third approach is suggested by Hasbrouck (1993) and is applied in this study.

Hasbrouck (1993) resolves a non-stationary time series of returns into a random-walk component and a residual stationary component. He assumes that the random-walk component represents the efficient price driven by information-based permanent changes and that the residual stationary component represents temporary price changes, which should quickly reverse. Thus, the observed log transaction prices $\left(p_{t}\right)$ can be decomposed into an efficient price $\left(m_{t}\right)$ and a pricing error $\left(s_{t}\right)$.

$p_{t}=m_{t}+s_{t}$

$r_{t}=\ln \left(p_{t} / p_{t}-1\right)$

Here $t$ is assumed to index stock transactions. It is assumed that the pricing error follows a zero-mean covariance-stationary process. Therefore, the standard error of the pricing error $\left(\sigma_{s}\right)$ can be interpreted as a measure of its magnitude. Given the zero-mean, the standard error describes how closely the observed transaction prices follow the efficient prices over time. Hasbrouck (1993) derives $\sigma_{s}$ from the vector autoregressive (VAR) model:

$$
\begin{aligned}
& r_{t}=a_{1} r_{t-1}+a_{2} r_{t-2}+\cdots+b_{1} x_{t-1}+b_{2} x_{t-2}+\cdots+v_{1, t} \\
& x_{t}=c_{1} r_{t-1}+c_{2} r_{t-2}+\cdots+d_{1} x_{t-1}+d_{2} x_{t-2}+\cdots+v_{2, t}
\end{aligned}
$$

where $x_{t}$ represents the signed trade volume, positive if the agent initiated the buy and negative if the agent initiated the sell. The variables $v_{l, t}$ and $v_{2, t}$ are the trade innovations which are zero-mean, serially uncorrelated disturbances.

For further calculations Hasbrouck (1993) transforms the VAR model in a vector moving average (VMA) model, expressing the exogenous variables in terms of current and lagged disturbances. 
$r_{t}=a_{0}^{*} v_{1, t}+a_{1}^{*} v_{1, t-1}+a_{2}^{*} v_{1, t-2}+\cdots+b_{0}^{*} v_{2, t}+b_{1}^{*} v_{2, t-1}+b_{2}^{*} v_{2, t-2}$

$x_{t}=c_{0}^{*} v_{1, t}+c_{1}^{*} v_{1, t-1}+c_{2}^{*} v_{1, t-2}+\cdots+d_{0}^{*} v_{2, t}+d_{1}^{*} v_{2, t-1}+d_{2}^{*} v_{2, t-2}$

Than, Hasbrouck (1993) shows that based on the pricing process (5), the vector autoregressive model (7) and the restriction suggested by Beveridge and Nelson (1981) the pricing error may be expressed as:

$s_{t}=\alpha_{0} v_{r, t}+\alpha_{1} v_{r, t-1}+\cdots+\beta_{10} v_{x, t}+\beta_{11} v_{x, t-1}$

while $\alpha$ and $\beta$ are computed as follows:

$\alpha_{j}=-\sum_{k=j+1}^{\infty} a_{k}^{*} \quad \beta_{j}=-\sum_{k=j+1}^{\infty} b_{k}^{*}$

Finally, we obtain the standard deviation of the pricing error $\sigma_{s}$ as:

$$
\sigma_{s}=\sum_{j=0}^{\infty}\left[\alpha_{j} \beta_{j}\right] \operatorname{cov}(v)\left[\begin{array}{c}
\alpha_{j} \\
\beta_{j}
\end{array}\right]
$$

To control for cross-section differences in return variance, we divide $\sigma_{s}(11)$ by the standard deviation of $r_{t}(6)$ and refer to it as $V R(s / p)$.

For estimating the returns: we exclude all transactions where the previous price differs by more than 30 percent. Additionally, we exclude in our sample of the VAR-model all observations including overnight returns.

Before estimating the pricing error the number of lags for the VAR model has to be defined. In the previous literature the numbers of lags vary to a large degree, because it is not possible to derive the number of lags theoretically. Thus, we apply the likelihood ratio as suggested by Sims (1980) to estimate the appropriate number of lags. In general, VAR model may differ in length of their lags. A longer lag model is viewed as unrestricted model, while a model with shorter lags is called restricted. Sims (1980) computes a likelihood ratio statistics to test for the significance of imposing the restrictions by deleting an additional lag from the model. If 
the restriction leads to a statistical significant degradation of the model, we conclude that the longer model is more appropriate. We compute the likelihood ratio across all securities and conclude that three lags are the most appropriate.

We require a minimum of seventy observations for estimating meaningful pricing errors. Additionally, to minimize the influence of outliers we exclude all securities with a pricing error larger than one. ${ }^{13}$ Unfortunately, most securities are not able to fulfill those requirements for trading during after-hours. Thus, we do not compute the pricing error for the sample of less liquid stocks and the sample of stocks with high trading volume is reduced to 27 securities.

Additionally, we provide a second more simple measure for the informational efficiency of prices, because of the restriction of $\operatorname{VR}(s / p)$. The second measure is the absolute transactionprice-return first-order autocorrelation and demands less data restrictions, but has a theoretical shortcoming. Nevertheless, we report this measure, as it provides further robustness of our results in combination with $V R(s / p)$. We compute this measure as follows: All transaction price information observed during a period of fifteen minutes are aggregated to one price information using the last price fixing (close) of this period. Using this price series, we compute returns and estimate absolute correlation coefficients, while ignoring overnightreturns. We refer to this measure as $|\operatorname{Corr} 15|$. It is assumed that efficient prices follow a random walk. The more a price series resembles a random walk, the less autocorrelation should be. We report the absolute autocorrelation, because we are interested in the deviation of the price series from the random walk but not in the direction. The shortcoming of this measure is as follows: While Hasbrouck (1993) distinguishes between information related and unrelated price changes, $|\operatorname{Corr} 15|$ does not. Applying an autocorrelation based measure ignores that autocorrelation is not necessarily induced by inefficient pricing but might be also caused by efficient price discovery. As for example an informed trader chooses to split his orders over time. Then, prices gradually incorporate information and cause a positive autocorrelation, even though all publicly available information are efficiently processed. Hence, this "efficient" autocorrelation leads to an overstating of $|\operatorname{Corr} 15|$. One feature of this study mitigates our concerns. We do not use $|\operatorname{Corr} 15|$ in an absolute sense. Our analysis focuses on the change of $|\operatorname{Corr} 15|$ around the change of opening times of Xetra. Our results

\footnotetext{
${ }^{13}$ Only one security in our sample.
} 
should be unbiased, under the assumption that the effect of "efficient" autocorrelation is constant over time. We see no reason, why this assumption should not hold true.

\section{2. $\quad$ Results}

Table VI presents an analysis of the informational efficiency at the FSE around the change in operating hours at Xetra. The sample is divided into "Before Nov. $3^{\text {rd }}, 2003$ " / "After Oct. $31^{\text {st }}, 2003$ ", trading between during regular hours (9:00 a.m. - 5:30 p.m.) / during evening hours (5:30 p.m. - 8:00 p.m.) and high / low trading volume. We use a variable constructed from the variance decomposition procedure in Hasbrouck (1993), referred to as $V R(s / p)$. Furthermore, we compute first-order autocorrelations of quote-midpoint returns of equally spaced 15-minutes-intervals, referred to as $|\operatorname{Corr} 15|$. We report medians across all securities. Pair-wise Mann-Whitney $U$ tests are used to test the null-hypothesis that two samples are drawn from identical populations.

The efficiency measures $V R(s / p)$ and $|\operatorname{Corr} 15|$ for stocks with low trading volume are not coherent across the sub-samples. While $V R(s / p)$ suggests a strong quality increase during regular operating hours, does $|\operatorname{Corr} 15|$ shows no changes. We interpret the results in the following way: Similar with our results for less liquid stocks in Section 6, we find some evidence that during regular operating hours a secular trend improves market efficiency. Furthermore, there is no evidence that evening hour trading is affected by the event.

Our results for highly liquid stocks are much more coherent. On the one hand, the pricing error and the first-order autocorrelation show that the market efficiency during regular business hours increased. This is in line with our expectations, because we showed in Section 5 that liquidity increased statistically significant. On the other hand, we observe that $V R(s / p)$ and $\mid$ Corr 15 $\mid$ during evening hours decreases. Even though our p-values are rather $(0.1003$ and 0.1989) weak, we still believe that they are meaningful. Firstly, the pricing error is very close to the 10 percent threshold. Secondly, those p-values are significantly smaller than the corresponding p-value (0.8105) for less liquid stocks. And thirdly, the weak p-values might be caused by the decreased sample, due to strict data requirements.

Thus we have to conclude that similar with our results in Section 6 we do not find any evidence that the event did have an effect on stocks with low trading volume. Furthermore, we present weak indication that the market quality decreased. In general these results are in 
line with our expectations. But it is a little bit surprising that the decrease of market quality for highly liquid stocks during evening hours is not stronger. Obviously is FSE able to provide own price discovery nearly as efficient as done by Xetra during the evening hours. These observations are in line with Hypothesis 3 and 4c.

\section{Conclusion}

In this study we investigated the changes at regional stock exchanges in Germany associated with the earlier closing of Xetra. Our particular focus has been on the affects on trading when the main stock exchange stops to operate. Our study contributes to the growing literature on parallel markets. While most studies focus on an increasing number of trading venues, we show what happens if potential trading channels decreases. We study a unique event, when the main trading platform Xetra reduces its operating hours. We provide evidence that the FSE is able to increase its liquidity on a stand alone basis. Furthermore, we observe that the probability of informed trading decreases during evening hours and approaches the same level as measured during regular operating hours. This is due to a stronger increase of arrival rates of uninformed traders compared to informed traders. Again, these observations hold only true for highly liquid stocks and not for less liquid stocks. Finally, we see that the informational efficiencies of transaction prices decrease weakly. This effect is most likely driven by the overall decrease in liquidity and a stronger increase of uninformed traders than informed traders. The pricing error does not decrease statistical significantly for stocks with low trading volume for trading during evening hours. This result is in line with our observation, as less liquid stocks do not increase liquidity or number of informed traders. All these results are in line with our expectations based on the existing literature. We are certain that our reported results are robust, because controlled for unobserved trends by estimating the measures for regular operating hours, too.

These results are important for the following reasons: This paper illustrates the impact of the changes of liquidity, informed trading and market efficiency when the home market stops to operate and regional stock exchanges are not able to profit from price discovery provided by the main stock exchange anymore. This study documents the dynamic behavior of investors on changes in market structure and presents evidence on the competitiveness of regional stock exchanges in Germany. We provide evidence that the market quality during evening hours decreased only weakly, suggesting that the FSE is able to provide price discovery independently at least for a few hours a day. Furthermore, we conclude that liquidity 
externalities do not have such a major impact that the overall performance of the FSE declines. This implies that evening hour trading yields added value, despite less favorable market conditions. Obviously, there are enough investors, which willingness for trading is less determined by trading conditions and more influenced by exogenous factors.

Finally, one last note of caution: Firstly, we are not able to estimate the direction and size of the effect caused by consolidation of order flow. As argued before, even theory is discordant on magnitude and direction of this effect. Secondly, our results are limited regarding a direct comparison with Xetra. In Section 5 and 6 we showed that liquidity increased and that the arrival rates of uninformed traders improved more than arrival rates of informed traders. Given our limited data, we are not able to estimate the fraction of order flow, which is captured by FSE from Xetra. This would provide further evidence on the behavior of investors when changes in market structure take place and is up for future research. 


\section{References}

Abhyankar, Abhay, Dipak Ghosh, E. Levin, and R. J. Limmack, 1997, Bid-Ask Spreads, Trading Volume and Volatility: Intra-Day Evidence from the London Stock Exchange, Journal of Business Finance \& Accounting 24, 343-362.

Amihud, Yakov, Beni Lauterbach, and Haim Mendelson, 2003, The Value of Trading Consolidation: Evidence from the Exercise of Warrants, Journal of Financial and Quantitative Analysis 38, 829-846.

Anand, Amber, and Terrence Martell, 2001, "Informed" Limit Order Trading, presented at 2002 Financial Management Association Annual Meeting, San Antonio, USA.

Arnold, Tom, Philip Hersch, J. Harold Mulherin, and Jeffry Netter, 1999, Merging Markets, The Journal of Finance 54, 1083-1107.

Barclay, Michael J., and Terrence Hendershott, 2003, Price Discovery and Trading After Hours, Review of Financial Studies 16, 1041-1073.

Barclay, Michael J., and Terrence Hendershott, 2004, Liquidity Externalities and Adverse Selection: Evidence from Trading after Hours, The Journal of Finance 59, 681-710.

Barclay, Michael J., Terrence Hendershott, and D. Timothy McCormick, 2003, Competition among Trading Venues: Information and Trading on Electronic Communications Networks, The Journal of Finance 58, 2637 - 2666.

Barnea, A., 1974, Performance evaluation of New York Stock Exchange specialists, Quarterly Journal of Economics 107, 797-817.

Baruch, Shmuel, 2005, Who Benefits from an Open Limit-Order Book?, Journal of Business $78,1267-1306$.

Battalio, Robert H., 1997, Third Market Broker-Dealers: Cost Competitors or Cream Skimmers?, The Journal of Finance 52, 341-352.

Bernhardt, Dan, and Eric Hughson, 1997, Splitting Orders, Review of Financial Economics $10,69-101$.

Beveridge, S., and C. Nelson, 1981, A New Approach to the Decomposition of Economic Time Series into Permandt and Transitory Components with Particular Attention to the Measurement of the 'Business Cycle', Journal of Monetary Economics 7, 151-174.

Biais, Bruno, 1993, Price Formation and Equilibrium Liquidity in Fragmented and Centralized Markets, The Journal of Finance 48, 157-185.

Bloomfield, Robert, Maureen O'Hara, and Gideon Saar, 2005, The "make" or "take" decision in an electronic market: Evidence on the evolution of liquidity, Journal of Financial Economics 75, 165-199.

Boehmer, Beatrice, and Ekkehart Boehmer, 2003, Trading your Neighbor's ETFs: Competition or Fragmentation, Journal of Banking \& Finance 27, 1667-1703. 
Boehmer, Ekkehart, Eric Kelley, and Christo Pirinsky, 2005, Institutional Investors and the Informational Efficiency of Prices, presented at the 2005 Spring Meeting of the NBER Microstructure Group.

Boehmer, Ekkehart, Gideon Saar, and Lei Yu, 2005, Lifting the Veil: An Analysis of Pretrade Transparency at the NYSE, The Journal of Finance 60, 783-815.

Chan, Kalok, Y. Peter Chung, and Wai-Ming Fong, 2002, The Informational Role of Stock and Option Volume, Review of Financial Studies 15, 1049-1075.

Chan, Kalok, Y. Peter Chung, and H. Johnson, 1995, The Intraday Behavior of Bid-Ask Spreads for NYSE Stocks and CBOE Options, Journal of Financial and Quantitative Analysis 30, 329-346.

Chordia, Tarum, Richard Roll, and Avanidhar Subrahmanyam, 2005, Liquidity and Market Efficiency, Working Paper, UCLA Anderson School of Management.

Chowdhry, Bagwan, and Vikram Nanda, 1991, Multimarket Trading and Market Liquidity, Review of Financial Studies 4, 483-511.

Commerton-Forde, Carole, and James Rydge, 2004, A Review of Stock Market Microstructure, Working Paper, SIRCA.

Conrad, Jennifer, Kevin M. Johnson, and Sunil Wahal, 2003, Institutional trading and alternative trading systems, Journal of Financial Economics 70, 99-134.

DeFontnouvelle, Patrick, Raymond P. H. Fishe, and Jeffrey H. Harris, 2000, The Behavior of Bid-Ask Spreads and Volume in Options Markets During the Competition for Listings in 1999, Working Paper, University of Miami.

Demarchi, Marianne, and Thierry Foucault, 2000, Equity Trading Systems in Europe: A Survey of Recent Changes, Annales D'Économie et de Statistique 60, 73-115.

Deutsche Börse, 2003, Factbook 2003, http://www3.deutscheboerse.com/INTERNET/IP/ip stats.nsf/(KIR+Factbook+Kassamarkt)/BD587F972E5 DF758C1256E850045DAEB/\$FILE/Factbook 2003 d.pdf?OpenElement.

Easley, David, Robert F. Engle, Maureen O'Hara, and Liuren Wu, 2000, Time-Varying Arrival Rates of Informed and Uninformed Trades, presented at American Finance Association Annual Meeting 2002, Atlanta.

Easley, David, Soeren Hvidkjaer, and Maureen O'Hara, 2002, Is Information Risk a Determinant of Asset Returns?, The Journal of Finance 57, 2185-2221.

Easley, David, Nicholas M. Kiefer, and Maureen O'Hara, 1997a, The information content of the trading process, Journal of Empirical Finance 4, 159-186.

Easley, David, Nicholas M. Kiefer, and Maureen O'Hara, 1997b, One Day in the Life of a Very Common Stock, Review of Financial Studies 10, 805-835.

Easley, David, Nicholas M. Kiefer, Maureen O'Hara, and Joseph B. Paperman, 1996, Liquidity, Information, and Infrequently Traded Stocks, The Journal of Finance 51, $1405-1436$. 
Fong, Kingsley, Ananth Madhavan, and Peter L. Swan, 2001, Why do Markets Fragment? A Panel-Data Analysis of Off-Exchange Trading, Working Paper, University of Sidney.

Glosten, Lawrence, 1994, Is the Electronic Open Limit Order Book Inevitable?, The Journal of Finance 49, 1127-1161.

Glosten, Lawrence, 1999, Introductory comments: Bloomfield and O'Hara, and Flood, Huismann, Koedijk, and Mahieu, Review of Financial Studies 12, 1-3.

Goldstein, Michael A., Bonny F. van Ness, and Robert A. van Ness, 2002, The Intraday Probability of Informed Trading, presented at Annual Meeting of Financial Management Association 2003, Denver USA.

Gouriéoux, C., J. Jasiak, and G. Le Fog, 1999, Intra-day market activity, Journal of Financial Markets 2, 193-226.

Grammig, Joachim, Dirk Schiereck, and Erik Theissen, 2000, Informationsbasierter Handel über IBIS, zfbf - Schmalenbachs Zeitschrift für betriebswirtschaftliche Forschung 52, 619-642.

Grammig, Joachim, Dirk Schiereck, and Erik Theissen, 2001, Knowing Me, Knowing You: Trader Anonymity and Informed Trading in Parallel Markets, Journal of Financial Markets 4, 385-412.

Hasbrouck, Joel, 1993, Assessing the Quality of a Security Market: A New Approach to Transaction-Cost Measurement, Review of Financial Studies 6, 191-212.

Hasbrouck, Joel, 1995, One security, many markets: Determining the contributions to price discovery, The Journal of Finance 50, 1175-1199.

Hasbrouck, Joel, and Robert A. Schwartz, 1988, An Assessment of Stock Exchange and Over-The-Counter Markets, Journal of Portfolio Management 14, 10-16.

Hautsch, Nikolaus, 2004. Modelling Irregularly Spaced Financial Data: Theory and Practice of Dynamic Duration Models (Springer, Berlin/Heidelberg/New York/Hong Kong/London/ Milan/Paris/Tokyo).

Hendershott, Terrence, and Charles P. Jones, 2005, Island Goes Dark: Transparency, Fragmentation and Regulation, Review of Financial Studies 18, 743-793.

Jain, Pankaj K., 2002, Institutional Design and Liquidity at Stock Exchanges around the World, Working Paper, University of Memphis.

Jain, Pankaj K., and G-H. Joh, 1988, The Dependence Between Hourly Prices and Trading Volume, Journal of Financial and Quantitative Analysis 33, 269-283.

Jain, Pankaj K., Christine X. Siang, Thomas H. McInish, and Nareerat Taechapiroontong, 2003, Informed Trading in Parallel Auction and Dealer Markets: An Analysis on the London Stock Exchange, presented at 14th Annual Conference on Financial Economics and Accounting.

Kyle, Albert S., 1985, Continuous Auctions and Insider Trading, Econometrica 53, 13151336. 
Madhavan, Ananth, 1995, Consolidation, Fragmentation, and the Disclosure of Trading Information, Review of Financial Economics 8, 579-603.

Madhavan, Ananth, 2000, Market Microstructure: A survey, Working Paper: University of Southern California.

Madhavan, Ananth, David Porter, and Daniel G. Weaver, 2005, Should securities markets be transparent?, Journal of Financial Markets 8, 265-287.

Mayhew, Stewart, 2002, Competition, Market Structure, and Bid-Ask Spreads in Stock Option Markets, The Journal of Finance 57, 931-958.

McInish, Thomas H., Bonny F. van Ness, and Robert A. van Ness, 2002, After-hours trading of NYSE stocks on the regional stock exchanges, Review of Financial Economics 11, 287-297.

McInish, Thomas H., and Robert A. Wood, 1992, An Analysis of Intraday Patterns in Bid / Ask Spread for NYSE Stocks, The Journal of Finance 47, 753-764.

Pagano, Marco, 1989a, Endogenous Market Thinness and Stock Price Volatility, Review of Economic Studies 56, 269-287.

Pagano, Marco, 1989b, Trading Volume and Asset Liquidity, Quarterly Journal of Economics $104,255-274$.

Reck, Martin, 2001, Call Market Mechanism on Deutsche Börse, in Robert A. Schwartz, Nicole Beiner, and Miriam J. Humbach, eds.: The Electronic Call Auction: Market Mechanism and Trading (Kluwe, Norwell / Dordrecht).

Schreiber, P. S., and Robert A. Schwartz, 1986, Price Discovery in Securities Markets, Journal of Portfolio Management 12, 43-48.

Sims, Christopher, 1980, Macroecomics and Reality, Econometrica 48, 1-48.

Theissen, Erik, 2001, Price Discovery and Screen Trading Systems, Working Paper, Bonn Econ Discussion Papers 35/2001.

Theissen, Erik, 2002, Floor versus Screen Trading: Evidence from the German Stock Market, Journal of Institutional and Theoretical Economics 158, 32-54.

Theissen, Erik, 2003a, Organized Equity Markets in Germany, Working Paper, Center for Financial Studies No. 2003/17.

Theissen, Erik, 2003b, Trades Anonymity, Price Formation and Liquidity, European Finance Review 7, 1-26.

Wahal, Sunil, 1997, Entry, Exit, Market Makers, and the Bid-Ask Spread, Review of Financial Economics 10, 871-901.

Wood, Robert A., Thomas H. McInish, and J. Keith Ord, 1985, An Investigation of Transaction Data for NYSE Stocks, The Journal of Finance 40, 723-739. 
Figure I: Equity Indices in Germany

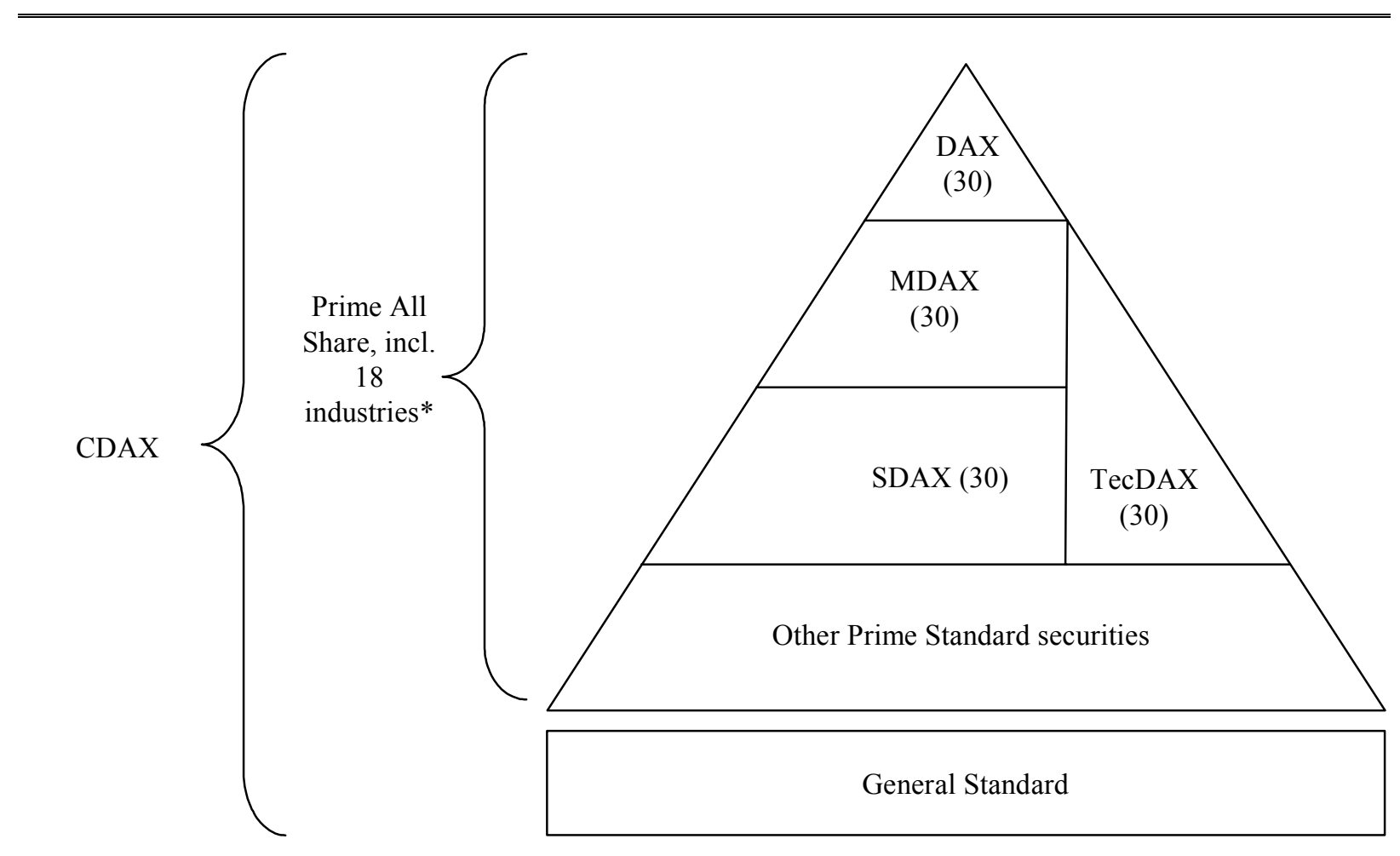

* Automobile, Banks, Basic Resources, Chemicals, Construction, Consumer, Financial Services, Food \& Beverages, Industrial, Insurance, Media, Pharma \& Healthcare, Retail, Software, Technology, Telecommunication, Transport \& Logistics, Utilities. Source: Theissen (2003a). 


\section{Figure II: Tree diagram of the trading process}

This figure presents the tree diagram of the trading process. The parameter $\mu(\varepsilon)$ is the arrival rate of (un)informed traders, $\alpha$ is the probability of an information event and $\delta$ is the probability that the information event is negative. Nodes to the left of the dotted line occur only once a day.

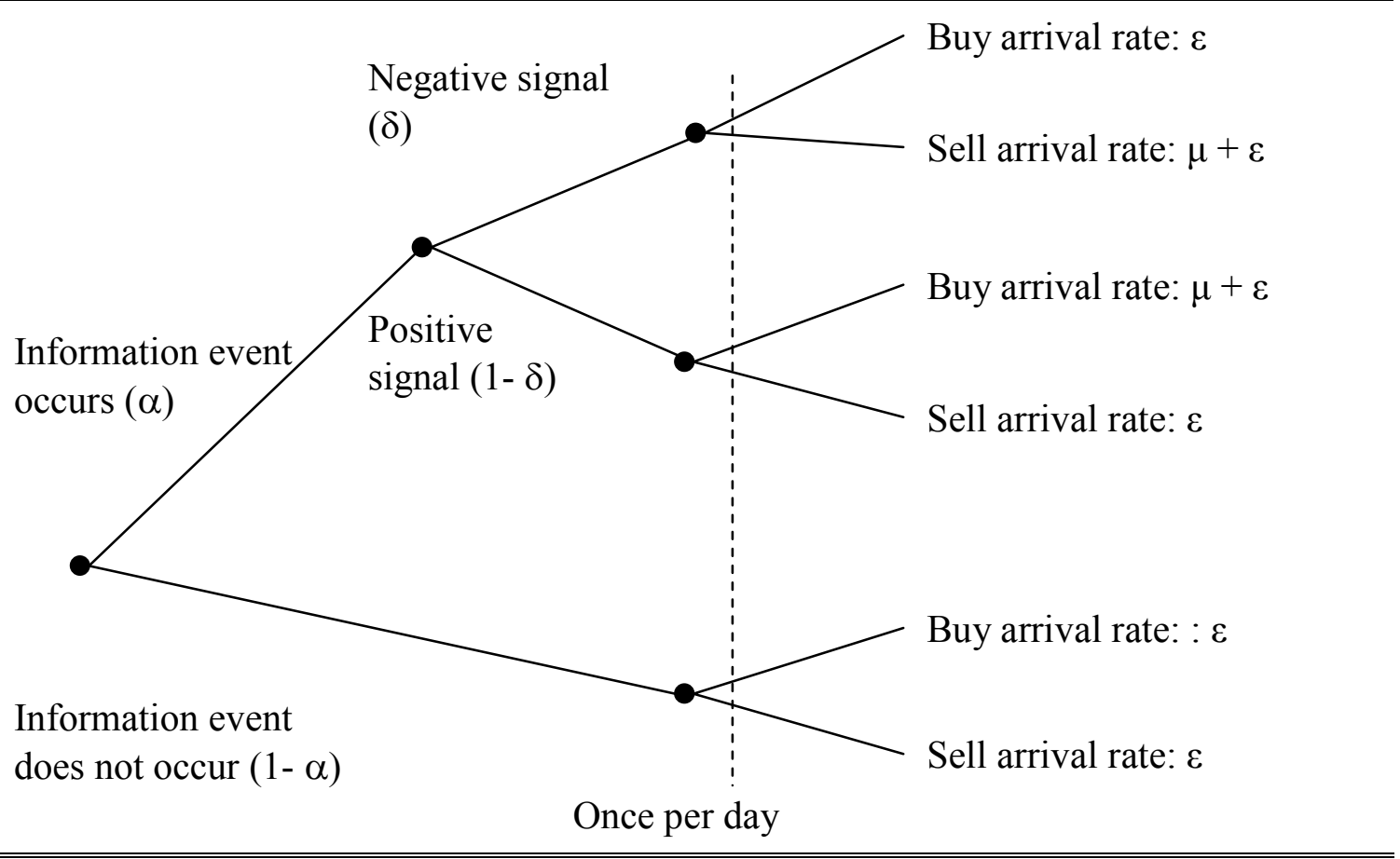

Source: Easley, Kiefer, O'Hara and Paperman (1996). 
Table I: Index Capitalization

This table presents the index capitalization (in Mio. Euro) for DAX, MDAX, SDAX, TecDAX and domestic equities for the year 2003.

\begin{tabular}{lccccc}
\hline \hline Month & DAX & MDAX & SDAX & TecDAX & Domestic Equities* \\
\hline Jan & 279,856 & 27,466 & & & 631,496 \\
Feb & 259,408 & 26,349 & & & 607,327 \\
Mar & 247,099 & 26,278 & 3,676 & 5,493 & 575,707 \\
Apr & 299,923 & 30,489 & 4,227 & 6,491 & 673,740 \\
May & 304,067 & 32,249 & 4,413 & 6,729 & 676,511 \\
Jun & 330,741 & 32,547 & 4,366 & 7,038 & 714,158 \\
Jul & 358,190 & 35,358 & 4,763 & 7,636 & 754,930 \\
Aug & 357,853 & 37,396 & 4,902 & 8,675 & 764,702 \\
Sep & 341,914 & 33,948 & 4,983 & 9,188 & 723,655 \\
Oct & 383,825 & 37,377 & 5,220 & 10,664 & 816,577 \\
Nov & 393,269 & 37,400 & 5,395 & 10,546 & 831,557 \\
Dec & 422,288 & 40,132 & 5,688 & 11,058 & 855,452 \\
\hline \hline
\end{tabular}

* Market capitalization figures are not freefloat-based.

Source: Deutsche Börse (2003). 
Table II: Market Shares of German Stock Exchanges

This table presents the total amount (in Mio. Euro) and the market shares of orderbook turnover of Xetra, FSE and all other exchanges cumulated in Germany for the indices DAX, MDAX, TecDAX and SDAX for the year 2003.

\begin{tabular}{lcccc}
\hline \hline & Xetra & FSE & Other exchanges & Total \\
\hline DAX & 716,096 & 16,564 & 6,436 & 739,096 \\
& $(96.89 \%)$ & $(2.24 \%)$ & $(0.87 \%)$ & $(100.00 \%)$ \\
MDAX & 31,712 & 2,866 & 627 & 35,205 \\
& $(90.08 \%)$ & $(8.14 \%)$ & $(1.78 \%)$ & $(100.00 \%)$ \\
SDAX & 1,700 & 792 & 152 & 2,644 \\
& $(64.30 \%)$ & $(29.95 \%)$ & $(5.75 \%)$ & $(100.00 \%)$ \\
TecDAX & 10,448 & 1,607 & 359 & 12,414 \\
& $(84.16 \%)$ & $(12.95 \%)$ & $(2.89 \%)$ & $(100.00 \%)$ \\
\hline \hline
\end{tabular}

Source: Deutsche Börse (2003). 
Table III: Descriptive Statistics

This table shows the descriptive statistics of the data and the securities included in the sample. Stocks are sorted according their Euro trading volume into two groups. All figures (except for number of securities) are equal-weighted means for the securities included in the group. Market value and free float are calculated for the October $1^{\text {st }}, 2003$. We report medians across securities. Pair-wise Mann-Whitney U tests are used to test the null-hypothesis that two samples are drawn from identical populations. Characteristics from the less liquid stock sample that differ from corresponding characteristics at the sample with highly liquid stocks at a $0.01 ; 0.05$ or 0.1 level are denoted with a $* * * ; * * ; *$, respectively.

\begin{tabular}{lrrr}
\hline \hline & $\begin{array}{r}\text { Low trading } \\
\text { volume }\end{array}$ & $\begin{array}{r}\text { High trading } \\
\text { volume }\end{array}$ & p-Value \\
\hline Number of securities & 39 & 40 & \\
Number of transactions per security & 2,554 & $12,089 * * *$ & 0.0000 \\
Market value per security in Mio. Euro & 1,133 & $7,492 * * *$ & 0.0000 \\
Free float per security in percent & $55.00 \%$ & $75.00 \%$ & 0.1153 \\
\hline \hline
\end{tabular}


Table IV: Trading Activities at the Frankfurt Stock Exchange (FSE)

This table shows an analysis of the liquidity at the FSE around the change in operating hours at Xetra. The sample is divided into "Before Nov. $3^{\text {rd }}, 2003$ " / "After Oct. $31^{\text {st }}, 2003$ ", trading between during regular hours (9:00 a.m. - 5:30 p.m.) / during evening hours (5:30 p.m. - 8:00 p.m.) and high / low trading volume. The following variables are reported: trade size in Euro $(T S)$, trade duration $(T D)$ and turnover duration $(T O D)$. We report medians across all trading sessions. Pair-wise Mann-Whitney $U$ tests are used to test the null-hypothesis that two samples are drawn from identical populations. Values after Oct. $31^{\text {st }}, 2003$ that differ from corresponding value before Nov. $3^{\text {rd }}, 2003$ at a $0.01 ; 0.05$ or 0.1 level are denoted with a ***; **; *, respectively.

\begin{tabular}{|c|c|c|c|c|c|}
\hline & & $\begin{array}{r}\text { Before Nov. } \\
3^{\text {rd }}, 2003 \\
\end{array}$ & $\begin{array}{l}\text { After Oct. } \\
31^{\text {st }}, 2003\end{array}$ & & p-Value \\
\hline \multicolumn{6}{|l|}{ Low Trading Volume } \\
\hline \multirow[t]{3}{*}{ Trading period: 9:00 a.m. - 5:30 p.m. } & $T S$ & 6,454 & 6,419 & & 0.6325 \\
\hline & $T D$ & $00: 15: 59$ & 00:11:13 & $* * *$ & 0.0000 \\
\hline & $T O D$ & 00:07:38 & 00:05:50 & $* * *$ & 0.0015 \\
\hline \multirow[t]{3}{*}{ Trading period: 5:30 p.m. - 8:00 p.m. } & $T S$ & 5,892 & 5,258 & & 0.6841 \\
\hline & $T D$ & 00:40:56 & 00:25:40 & $* * *$ & 0.0000 \\
\hline & $T O D$ & 00:17:05 & 00:12:22 & $* * *$ & 0.0050 \\
\hline \multicolumn{6}{|l|}{ High Trading Volume } \\
\hline \multirow{3}{*}{ Trading period: 9:00 a.m. - 5:30 p.m. } & $T S$ & 7,882 & 8,061 & & 0.7052 \\
\hline & $T D$ & 00:02:21 & 00:01:47 & $* * *$ & 0.0001 \\
\hline & $T O D$ & 00:00:54 & 00:00:34 & $* * *$ & 0.0000 \\
\hline \multirow[t]{3}{*}{ Trading period: 5:30 p.m. - 8:00 p.m. } & $T S$ & 6,965 & 12,261 & $* * *$ & 0.0000 \\
\hline & $T D$ & 00:07:49 & 00:04:24 & $* * *$ & 0.0000 \\
\hline & $T O D$ & 00:02:55 & 00:01:01 & $* * *$ & 0.0000 \\
\hline
\end{tabular}


Table V: Summary Parameter Estimates Statistics:

Probability of information based trading at Frankfurt Stock Exchange (FSE)

This table shows an analysis of the probability of informed trading at the FSE around the change in operating hours at Xetra. The sample is divided into "Before Nov. $3^{\text {rd }}, 2003$ " / "After Oct. 31 3 st 2003 ", trading between during regular hours (9:00 a.m. - 5:30 p.m.) / during evening hours (5:30 p.m. - 8:00 p.m.) and high / low trading volume. The parameter $\mu(\varepsilon)$ is the arrival rate of (un)informed traders, $\alpha$ is the probability of an information event and $\delta$ is the probability that the information event is negative. The parameter PIN measures the probability of information based trading. We report medians across all securities. Pair-wise Mann-Whitney U tests are used to test the null-hypothesis that two samples are drawn from identical populations. Values after Oct. $31^{\text {st }}, 2003$ that differ from corresponding value before Nov. $3^{\text {rd }}, 2003$ at a $0.01 ; 0.05$ or 0.1 level are denoted with a $* * * ; * * ; *$, respectively.

\begin{tabular}{|c|c|c|c|c|c|}
\hline & & $\begin{array}{r}\text { Before Nov. } \\
3^{\text {rd }}, 2003 \\
\end{array}$ & $\begin{array}{l}\text { After Oct. } \\
31^{\text {st }}, 2003 \\
\end{array}$ & & p-Value \\
\hline \multicolumn{6}{|l|}{ Low Trading Volume } \\
\hline \multirow[t]{6}{*}{ Trading day between 9a.m.-5:30p.m. } & $\alpha$ & 0.342 & 0.327 & & 0.5841 \\
\hline & $\delta$ & 0.546 & 0.646 & & 0.1270 \\
\hline & $\varepsilon$ & 10.815 & 16.184 & $* * *$ & 0.0004 \\
\hline & $\mu$ & 12.311 & 21.456 & $* * *$ & 0.0013 \\
\hline & $P I N$ & 0.187 & 0.180 & & 0.9846 \\
\hline & $\varepsilon / \mu^{\#}$ & 0.879 & 0.754 & & \\
\hline \multirow[t]{6}{*}{ Trading day between 5:30p.m.-8:00p.m. } & $\alpha$ & 0.200 & 0.183 & & 0.2738 \\
\hline & $\delta$ & 0.365 & 0.415 & & 0.6815 \\
\hline & $\varepsilon$ & 0.863 & 1.068 & & 0.1891 \\
\hline & $\mu$ & 2.175 & 2.432 & & 0.4601 \\
\hline & $P I N$ & 0.271 & 0.210 & & 0.2738 \\
\hline & $\varepsilon / \mu^{\#}$ & 0.397 & 0.439 & & \\
\hline \multicolumn{6}{|l|}{ High Trading Volume } \\
\hline \multirow[t]{6}{*}{ Trading day between 9a.m.-5:30p.m. } & $\alpha$ & 0.376 & 0.325 & & 0.4563 \\
\hline & $\delta$ & 0.631 & 0.660 & & 0.4352 \\
\hline & $\varepsilon$ & 51.792 & 84.145 & & 0.1525 \\
\hline & $\mu$ & 112.211 & 137.227 & & 0.1302 \\
\hline & PIN & 0.207 & 0.201 & & 0.9906 \\
\hline & $\varepsilon / \mu^{\#}$ & 0.462 & 0.613 & & \\
\hline \multirow[t]{6}{*}{ Trading day between 5:30p.m.-8:00p.m. } & $\alpha$ & 0.289 & 0.248 & & 0.1328 \\
\hline & $\delta$ & 0.574 & 0.364 & $* *$ & 0.0333 \\
\hline & $\varepsilon$ & 4.089 & 7.891 & $* * *$ & 0.0061 \\
\hline & $\mu$ & 12.496 & 20.880 & $*$ & 0.0510 \\
\hline & PIN & 0.271 & 0.201 & $* * *$ & 0.0003 \\
\hline & $\varepsilon / \mu^{\#}$ & 0.327 & 0.378 & & \\
\hline
\end{tabular}

\# This parameter is estimated based on the reported $\varepsilon$-and $\mu$-values. Thus no additional pairwise Mann-Whitney $U$ test is applied. 
Table VI: Informational Efficiency at the Frankfurt Stock Exchange (FSE)

This table shows an analysis of the informational efficiency at the FSE around the change in operating hours at Xetra. The sample is divided into "Before Nov. $3^{\text {rd }}, 2003$ " / "After Oct. $31^{\text {st }}, 2003$ ", trading between during regular hours (9:00 a.m. - 5:30 p.m.) / during evening hours (5:30 p.m. - 8:00 p.m.) and high / low trading volume. We use a variable constructed from the variance decomposition procedure in Hasbrouck (1993), referred to as $V R(s / p)$. Furthermore, we compute first-order autocorrelations of quote-midpoint returns of equally spaced 15-minutes-intervals, referred to as $|\operatorname{Corr} 15|$. We report medians across all securities. Pair-wise Mann-Whitney $U$ tests are used to test the null-hypothesis that two samples are drawn from identical populations. Values after Oct. $31^{\text {st }}, 2003$ that differ from corresponding value before Nov. $3^{\text {rd }}, 2003$ at a $0.01 ; 0.05$ or 0.1 level are denoted with a $* * * ; * * ; *$, respectively.

\begin{tabular}{|c|c|c|c|c|c|}
\hline & & $\begin{array}{r}\text { Before Nov. } \\
3^{\text {rd }}, 2003 \\
\end{array}$ & $\begin{array}{l}\text { After Oct. } \\
31^{\text {st }}, 2003 \\
\end{array}$ & & $\mathrm{p}$-Value \\
\hline \multicolumn{6}{|l|}{ Low Trading Volume } \\
\hline \multirow[t]{2}{*}{ Trading day between 9a.m.-5:30p.m. } & $V R(s / p)$ & 0.411 & 0.284 & $* * *$ & 0.0000 \\
\hline & $\mid$ Corr 15 | & 0.033 & 0.042 & & 0.8494 \\
\hline \multirow[t]{2}{*}{ Trading day between 5:30p.m.-8:00p.m. } & $V R(s / p)$ & $-/{ }^{\#}$ & $-/-^{\#}$ & & \\
\hline & $|\operatorname{Corr} 15|$ & 0.035 & 0.050 & & 0.8105 \\
\hline \multicolumn{6}{|l|}{ High Trading Volume } \\
\hline \multirow[t]{2}{*}{ Trading day between 9a.m.-5:30p.m. } & $V R(s / p)$ & 0.321 & 0.260 & $* * *$ & 0.0001 \\
\hline & $\mid$ Corr15| & 0.106 & 0.086 & $*$ & 0.0727 \\
\hline \multirow[t]{2}{*}{ Trading day between 5:30p.m.-8:00p.m. } & $V R(s / p)$ & 0.352 & 0.433 & & 0.1003 \\
\hline & $\mid$ Corr 15 $\mid$ & 0.086 & 0.123 & & 0.1989 \\
\hline
\end{tabular}

\# Measure could not be calculated due to insufficient amount of data. 